\title{
Four-year clinical remission of type 1 diabetes mellitus in two patients treated with sitagliptin and vitamin D3
}

\author{
Marcelo Maia Pinheiro', Felipe Moura Maia Pinheiro² and Margareth Afonso Torres ${ }^{3}$ \\ 1Pharmaceutical Assistance Center of the State of Mato Grosso, Cuiaba, Brazil, 2Faculdade de Medicina \\ da Universidade de Cuiabá-UNIC, Cuiaba, Brazil, and 'Laboratório Clinico do Hospital Israelita \\ Albert Eistein, São Paulo, SP, Brazil
}

\author{
Correspondence \\ should be addressed \\ to M M Pinheiro \\ Email \\ marcelopinheiro@ses.mt. \\ gov.br
}

\section{Summary}

Type 1 diabetes mellitus (T1DM) is a chronic disease characterized by autoimmune destruction of pancreatic beta cells and inadequate insulin production. Remission criteria in T1DM take into account serum levels of C-peptide and glycosylated hemoglobin, as well as the dose of insulin administered to the patient. However, remission of T1DM lasting longer than 1 year is rare. We describe here the cases of two young women who presented with positive glutamic acid decarboxylase (GAD) antibody and classic clinical manifestations of T1DM. Both patients had a prior history of Hashimoto's thyroiditis. They were initially treated with a basal-bolus regimen of insulin (glargine and lispro/glulisine). Once their blood glucose levels were controlled, they were started on oral sitagliptin $100 \mathrm{mg}$ and vitamin D3 $5000 \mathrm{IU}$ daily. After this therapy, both patients achieved clinical diabetes remission for 4 years, along with a decrease in anti-GAD antibody levels. These benefits were probably associated with immunological effects of these medications. Inhibition of dipeptidyl peptidase 4 (DPP-4) in animal models deregulates Th1 immune response, increases secretion of Th2 cytokines, activates $\mathrm{CD} 4{ }^{+} \mathrm{CD} 25^{+} \mathrm{FoxP} 3^{+}$ regulatory T-cells and prevents IL-17 production. Vitamin D3 also activates CD4+CD25+FoxP3+ regulatory T-cells, and these medications combined can improve the immune response in patients with new-onset T1DM and probably promote sustained clinical remission.

\section{Learning points:}

- The use of sitagliptin and vitamin D3 in patients with new-onset type 1 diabetes mellitus (T1DM) may help decrease the daily insulin requirement by delaying beta cell loss and improving endogenous insulin production.

- The use of sitagliptin and vitamin D3 in new-onset T1DM could help regulate the imbalance between Th17 and Treg cells.

- Age 14 years or above, absence of ketoacidosis and positive C-peptide levels in patients with T1DM are good criteria to predict prolonged T1DM remission.

- The determination of anti-GAD antibodies and C-peptide levels could be helpful in the follow-up of patients in use of sitagliptin and vitamin D3, which could be associated with prolonged T1DM clinical remission.

\section{Background}

Type 1 diabetes mellitus (T1DM) is a chronic disease characterized by hyperglycemia resulting from a destruction of pancreatic beta cells by a damaging and complex autoimmune process with activation of macrophages, dendritic cells and $\mathrm{CD}^{+}, \mathrm{CD}^{+}$and $\mathrm{B}$ lymphocytes. An interaction of these cells triggers an 
immune response that leads to insulitis, with activated $\mathrm{CD}^{+}$cytotoxic $\mathrm{T}$ lymphocytes often detected in analyses of pancreatic islets infiltrates (1). In addition, patients with T1DM have an imbalance between anti-inflammatory Treg cells (decreased function) and inflammatory Th17 cells (increased function) (2). The continuous destruction of beta cells decreases the patient's insulin secretory capacity, and by the time, the mass of beta cells reduces to less than $20 \%$ of their initial amount, clinical diabetes occurs (3). Patients with T1DM often experience a partial remission of the disease (honeymoon phase), although a remission lasting more than 1 year is uncommon. In general terms, partial remission is defined as a daily requirement of insulin $<0.5 \mathrm{IU} / \mathrm{kg}$ and levels of $\mathrm{HbA1c}$ $<6 \%$ and stimulated C-peptide $>0.90 \mathrm{ng} / \mathrm{mL}(4,5)$.

Dipeptidyl peptidase 4 (DPP-4) inhibitors, such as sitagliptin, have been used over the past few years to reestablish immunological tolerance and have successfully prevented and even reversed T1DM in nonobese diabetic mice (NOD) $(6,7)$. In humans, a few outcomes have also been demonstrated (8). Vitamin D, in turn, displays actions on the immune system, including effects on innate and acquired immunity. This evidence provides a rationale for the therapeutic use of vitamin $\mathrm{D}$ in the context of both prevention and treatment of the immune dysregulation that occurs in patients with T1DM (9).

We report here the cases of two young women with positive glutamic acid decarboxylase (GAD) antibodies and classic clinical manifestations of T1DM who achieved clinical remission for 4 years after treatment with sitagliptin and vitamin D3.

\section{Case presentation}

Patient \#1 was a 20-year-old woman with a history of hypothyroidism due to Hashimoto's thyroiditis treated since the age of 6 years with levothyroxine. In April 2012, she presented with weight loss, polyuria, polydipsia and leg cramps. Her physical examination was normal; she weighed $62 \mathrm{~kg}$, had a body mass index (BMI) of $21.7 \mathrm{~kg} / \mathrm{m}^{2}$ and blood pressure of $100 / 60 \mathrm{mmHg}$. She had a grandmother with Hashimoto's thyroiditis and type 2 diabetes mellitus.

Patient \#2 was a 21-year-old woman who presented in May 2011 with weight loss, polyuria, polydipsia and leg cramps. Her physical examination was normal; she weighed $62.5 \mathrm{~kg}$, had a BMI of $19.5 \mathrm{~kg} / \mathrm{m}^{2}$ and blood pressure of 115/70 mmHg. Her mother had Hashimoto's thyroiditis, and her brother had Crohn's disease.

\section{Investigation}

The diagnosis of diabetes mellitus was confirmed in patient \#1 based on her serum glucose and HbA1c levels (Fig. 1 and Table 1). The patient's anti-GAD antibody was positive (Fig. 2), her urinalysis revealed glycosuria without ketonuria and her serum levels of lipids, blood urea nitrogen (BUN) and creatinine were normal. Her HLA typing was DQA1*01:01, 03:01, DQB1*03:02, 05:01, DRB1*04:01, 10:01. Of note, the occurrence of the haplotype HLA-DQA1*03:01, -DQB1*03:02, -DRB1*04:01 is associated with an increased risk of T1DM.

In patient \#2, the diagnosis of diabetes mellitus was also confirmed by serum glucose and HbA1c levels (Fig. 1 and Table 1). The patient's anti-GAD antibody was positive (Fig. 2), her urinalysis revealed glycosuria without ketonuria, and her serum levels of lipids, BUN and creatinine were normal. Antithyroid antibodies measurement (Table 1) and thyroid ultrasound evaluation confirmed the diagnosis of Hashimoto's thyroiditis with a normal TSH level $(1.83 \mu \mathrm{IU} / \mathrm{mL})$. Her HLA typing was DQA1*01:01，01:01，DQB1*05:01，05:01， DRB1*01:01,
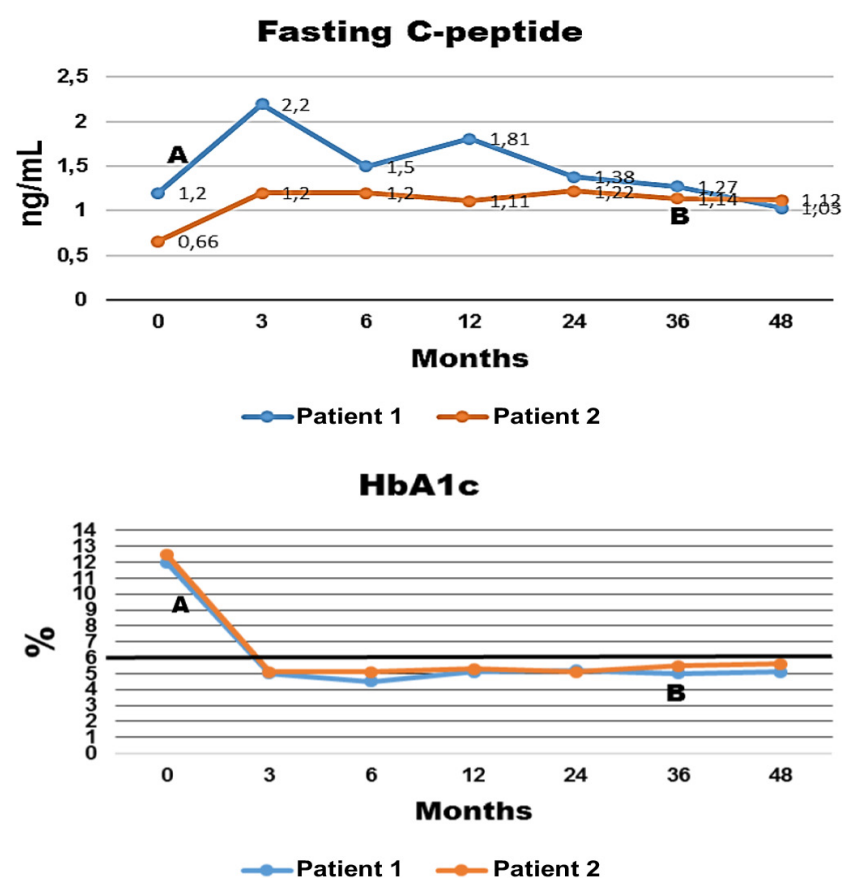

Figure 1

Fasting C-peptide levels (ELISA, reference values: $0.9-7.1 \mathrm{ng} / \mathrm{mL}$ ) and $\mathrm{HbA} 1 \mathrm{c}$ levels (high-performance liquid chromatography, HPLC), reference values: $4-6 \%$ ) over time (months of treatment). Treatment with sitagliptin and vitamin D3 started at 0 month. Point $A$ - interruption of insulin glargine and lispro (patient \#1), point B - interruption of insulin glargine (patient \#2). All tests were performed in the same clinical laboratory (Carlos Chagas, Cuiabá, Brazil) 
Table 1 Comparison between anthropometric and laboratory tests at baseline and after 4 years of treatment with sitagliptin and vitamin D3 in two young women with type 1 diabetes mellitus.

\begin{tabular}{l} 
Use of sitagliptin and \\
vitamin D3 (at baseline and \\
after 4 years of treatment) \\
\hline Patient \#1 \\
Baseline \\
4 years \\
Patient \#2 \\
Baseline \\
4 years \\
\hline
\end{tabular}

$\begin{array}{r}\hline \text { FBG } \\ \text { (mg/dL) } \\ \hline 320 \\ 82 \\ \\ 303 \\ 85 \\ \hline\end{array}$

\begin{tabular}{l}
$\begin{array}{c}\text { Weight } \\
(\mathrm{kg})\end{array}$ \\
\hline \\
62 \\
75 \\
62.5 \\
63 \\
\hline
\end{tabular}

\begin{tabular}{c}
$\begin{array}{c}\text { BMI } \\
\left(\mathrm{kg} / \mathrm{m}^{2}\right)\end{array}$ \\
\hline \\
21.7 \\
26.2 \\
\\
19.5 \\
19.66 \\
\hline
\end{tabular}

\begin{tabular}{c}
\hline $\begin{array}{c}\text { Calcium } \\
\text { (mg/dL) }\end{array}$ \\
\hline 10 \\
9 \\
9.6 \\
8.9 \\
\hline
\end{tabular}

\begin{tabular}{c}
$\begin{array}{c}\text { Vitamin D } \\
(\mathrm{ng} / \mathrm{mL})\end{array}$ \\
\hline \\
22.1 \\
43.7 \\
55.8 \\
62.5 \\
\hline
\end{tabular}

\begin{tabular}{l}
$\begin{array}{c}\text { Insulin dose } \\
(\mathrm{IU} / \mathrm{kg})\end{array}$ \\
\hline \\
0.79 \\
0 \\
0.55 \\
0.19 \\
\hline
\end{tabular}

\begin{tabular}{cccc}
\hline $\begin{array}{c}\text { Anti-TPO } \\
(\mathrm{IU} / \mathrm{mL})\end{array}$ & & $\begin{array}{c}\text { Anti-TG } \\
(\mathrm{IU} / \mathrm{mL})\end{array}$ \\
\cline { 1 - 1 } 452 & & 70.7 \\
24.65 & & 29.5 \\
& & \\
36.2 & & 197 \\
13.5 & & 82.6 \\
\hline
\end{tabular}

Reference values: $25(\mathrm{OH})$ vitamin D (ELISA): $30-100 \mathrm{ng} / \mathrm{mL}$, anti-TPO (ELISA): $<35 \mathrm{IU} / \mathrm{mL}$, anti-TG (ELISA): $<40 \mathrm{IU} / \mathrm{mL}$, calcium: $8.5-10.5 \mathrm{mg} / \mathrm{dL}$ (colorimetric, Arsenazo III). All tests were performed in the same laboratory (Carlos Chagas, Cuiabá, Brazil).

anti-TG, antithyroglobulin antibody; anti-TPO, antithyroperoxidase antibody; BMI, body mass index; FBG, fasting blood glucose.

01:01, which is not associated with an increased risk of T1DM.

\section{Treatment}

Patient \#1 started treatment with insulin glargine $35 \mathrm{IU}$ once a day and insulin lispro 2 IU before breakfast and 6 IU before lunch and dinner. On May 2012, she started treatment with sitagliptin $100 \mathrm{mg} /$ day and vitamin D3 $5000 \mathrm{IU} /$ day, and on June 6, 2012, she interrupted the administration of insulin.

Patient \#2 started treatment with insulin glargine $20 \mathrm{IU}$ once a day, and insulin glulisine $6 \mathrm{IU}$ before breakfast, lunch and dinner. In July 2011, she experienced a honeymoon phase in which she used only insulin glargine 6-10IU/day. Two months later, she resumed a basal-bolus regimen with the same initial doses.

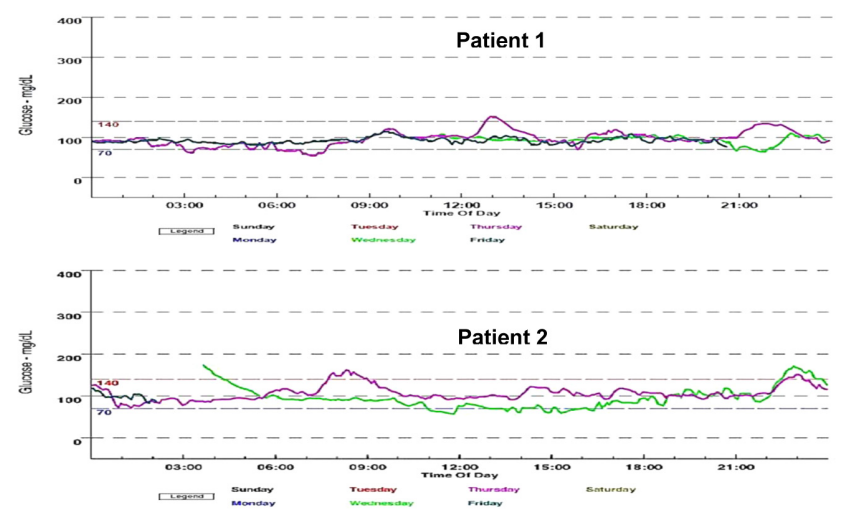

Figure 2

Evaluation with a continuous glucose monitoring system (CGMS) during 72 h. Top graph: patient \#1, obtained in May 2014. Bottom graph: patient \#2, obtained in May 2014.
In March 2012, she was started on sitagliptin $100 \mathrm{mg} /$ day and vitamin D3 5000 IU/day.

Both patients were duly informed that treatment of T1DM with sitagliptin and vitamin D3 was off-label and signed an informed consent form, accepting this treatment.

\section{Outcome and follow-up}

Patient \#1 continues treatment with sitagliptin and vitamin D3. Since June 6, 2012, she has not used insulin and her levels of capillary glucose and serum fasting glucose, HbA1c and C-peptide remain normal (Fig. 1). In May 2014, her glucose levels, determined with a continuous glucose monitoring system (CGMS$72 \mathrm{~h})$, confirmed the persistence of normal glucose values (Fig. 2).

After 1 month of treatment with sitagliptin and vitamin D3, patient \#2 started decreasing her insulin dose, and in March 2015, she interrupted the administration of insulin glargine. At the time of this report, she was only administering insulin glulisine 2-4 IU before breakfast, lunch and dinner when eating carbohydrates and she maintains use of sitagliptin and vitamin D3. She chose not to interrupt the use of insulin glulisine to maintain flexibility in her diet. She has been maintaining normal levels of capillary glucose, fasting blood glucose, HbA1c and C-peptide (Fig. 1). Results from her CGMS-72 h in May 2014 were normal (Fig. 2).

Both patients maintained normal serum levels of calcium and $25(\mathrm{OH})$ vitamin $\mathrm{D}$. No side effects related to sitagliptin use have been reported by the patients. 


\section{Discussion}

The importance of these cases lies in the fact that both patients with T1DM have been maintaining disease remission for prolonged periods, which in the first patient is occurring without administration of insulin. Patient \#2 experienced a honeymoon phase before starting therapy with sitagliptin and vitamin D3. Both patients presented all criteria for diabetes remission, including a daily requirement of insulin $<0.5 \mathrm{IU} / \mathrm{kg}, \mathrm{HbA} 1 \mathrm{c}$ $<6 \%$ and C-peptide levels $>0.90 \mathrm{ng} / \mathrm{mL}$. Of note, both patients presented early and significant decreases in antiGAD levels, which remained below the baseline levels throughout a follow-up period of 48 months (Fig. 3). Anti-GAD levels tend to remain elevated in patients with positive C-peptide levels, reflecting a chronic antigenic stimulation. Both patients had a diagnosis of Hashimoto's thyroiditis when they presented with signs of overt T1DM and had positive antithyroid antibodies during follow-up. Patient \#1 had positive levels of antithyroid antibodies since the age of 6 years, even during use of levothyroxine; however, the levels decreased after treatment with sitagliptin and vitamin D3 (Table 1) while she maintained use of levothyroxine $125 \mu \mathrm{g} /$ day. Only one of the patients presented an HLA-DRDQ haplotype associated with an increased risk of diabetes, but the progression of the patients was similar regardless of the presence of this haplotype. It is possible that the favorable outcome presented by the patients may be due to a good pancreatic insulin reserve (both had positive fasting C-peptide levels) when they were diagnosed with T1DM. In addition, none of the patients presented ketoacidosis on diagnosis and both were older than 14 years; all these characteristics are

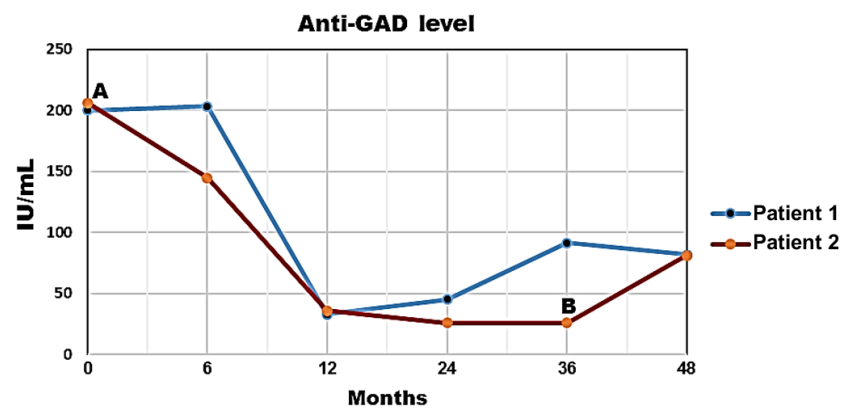

Figure 3

Progression of anti-glutamic acid decarboxylase (GAD) antibody levels over time (months of treatment). Treatment with sitagliptin and vitamin D3 started at 0 month. Point A: interruption of insulin glargine and lispro (patient \#1), point B: interruption of insulin glargine (patient \#2). Anti-GAD antibodies were measured with ELISA (reference value: $<10 \mathrm{IU} / \mathrm{mL}$ ). All tests were performed in the same clinical laboratory (Carlos Chagas, Cuiabá, Brazil). markers of spontaneous remission during the first year of insulin treatment. In contrast, the detection of anti-GAD antibodies is a known independent marker of decreased C-peptide secretion at 6 months (10); however, the levels of C-peptide did not decrease in the present cases. In fact, even without insulin, patient \#1 maintains HbA1c levels $<6 \%$ (Fig. 1) and an increased BMI after 4 years of follow-up (Table 1).

Even though sitagliptin is not approved for the treatment of T1DM, we recommended this drug as an off-label treatment for these patients based on a growing body of evidence demonstrating that sitagliptin and other DPP-4 inhibitors are able to decrease the daily insulin requirement and improve metabolic control in patients with T1DM without exacerbating the risk of hypoglycemia $(11,12,13)$. Another case of T1DM remission for 1 year in a patient treated with sitagliptin has been previously reported in this journal (14). It may be too early to conclusively assert that an unusually long remission observed in only two cases of T1DM could be attributed to sitagliptin and vitamin D3. However, findings in animal models have suggested that the benefits observed in clinical trials of sitagliptin in T1DM patients are associated with the immunological effects of the drug. Lymphocytes have a membrane-associated protein with DPP-4 activity - CD26 - which has a marked influence on the development, migration and production of cytokines by T cells. Bengsch et al. (15) have shown that $\mathrm{T}$ helper cells (Th17) have the highest CD26 expression

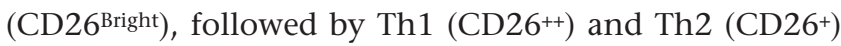
cells, whereas the lowest levels were found in Treg cells (CD26 low/-) (Fig. 4). Our group has previously shown that sitagliptin is able to increase the secretion of Th2 cytokine (IL-4), decrease the secretion of Th1 cytokine (IFN- $\gamma$ ) and prevent the production of Th17 cytokine (IL-6) by human

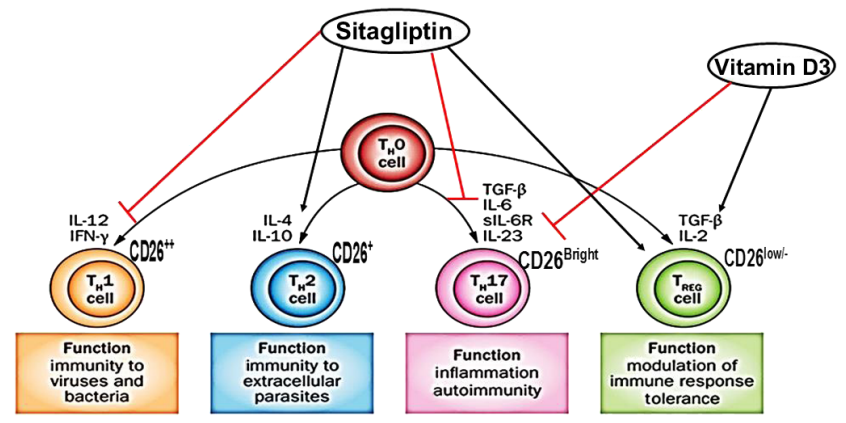

Figure 4

Cytokines involved in the differentiation of naïve cells to different types of Th cells, expression of CD26 in lymphocytes and probable mechanistic effects of the association between sitagliptin and vitamin D3 in inducing immunotolerance in type 1 diabetes mellitus. 
peripheral lymphocytes in vitro (16). Inhibition of DPP-4 in animal models modulates the Th1 immune response, increases the secretion of Th2 cytokines, activates $\mathrm{CD}^{+}{ }^{+} \mathrm{CD} 25+{ }^{+}{ }^{2} \times \mathrm{P}^{+}+$regulatory T-cells (Treg) and prevents IL-17 production (17). The immunoregulatory effects of DPP-4 inhibition have been reported in humans (18), and the effects of sitagliptin in patients with psoriasis have been recently documented $(19,20)$. Of note, a case report has shown that sitagliptin treatment of a patient with autoimmune diabetes and stiff-person syndrome significantly decreased the patient's serum HbA1c level from 9.3\% to 5.2\% two years after treatment and decreased anti-GAD antibody levels by $85 \%$ after 18 months (21). In patients with latent autoimmune diabetes of adults (LADA), treatment with sitagliptin and insulin maintained the beta cell function when compared with insulin alone (22).

Recent evidence suggests that vitamin D plays a role in the pathogenesis and prevention of T1DM. Active vitamin D - 1 $\alpha, 25(\mathrm{OH}) 2 \mathrm{D} 3$ - prevents T1DM in animal models, modifies T-cell differentiation, modulates dendritic cell action and induces cytokine secretion, shifting the balance to regulatory T-cells (23). Moreover, vitamin D supplementation in early childhood has been associated with a decreased risk of T1DM (24). Rapti et al. (25) presented a case of a 31-year-old man with LADA treated with a combination of metformin $850 \mathrm{mg}$ and sitagliptin $50 \mathrm{mg}$ twice daily along with vitamin D supplementation (2000 IU/day). After treatment, the patient's serum HbA1c level decreased from $9.6 \%$ to $5.2 \%$ and his positive antiGAD level (which was $32 \mathrm{IU} / \mathrm{mL}$ at baseline) became negative. During 2 years without insulin, the patient maintained an excellent blood glucose profile. Li et al. (26) showed that 1- $\alpha$-hydroxyvitamin D3 combined with insulin therapy preserves the pancreatic beta cell function in patients with LADA with a maximum diabetes duration of 1 year.

In conclusion, prolonged remission is possible in patients with new-onset T1DM. Sitagliptin inhibition of CD26/DPP-4 in the immune cells and an incretin effect (increasing the half-life of glucagon-like peptide-1, GLP-1) on beta cells could explain the beneficial effects observed in the cases presented here. A growing body of evidence shows that DPP-4 inhibitors and vitamin D3 are able to modulate the immune response - as both drugs may decrease the inflammatory cytokine IL- 6 and enhance the suppressive effects of Treg cells (Fig. 4) - and have direct anti-apoptotic effects on beta cells $(27,28,29)$. Still, new trials of DPP-4 inhibitors and vitamin D3 in patients with T1DM should be conducted to confirm their safety and efficacy in these patients. The decrease in antibodies levels in the cases reported here, as well as in others reported in the literature, reinforces this hypothesis since patients with T1DM older than 14 years of age and with positive anti-GAD levels only show a decrease in anti-GAD levels after 5 years (30). Large trials are still needed to confirm this theory.

\section{Declaration of interes}

The authors declare that there is no conflict of interest that could be perceived as prejudicing the impartiality of the research reported.

\section{Funding}

This study was conducted without grants or funding from agencies in the public, commercial and not-for-profit sector.

\section{Patient consent}

We obtained written informed consents from all patients for publication of this case report.

\section{Author contribution statement}

Marcelo Maia Pinheiro was the endocrinologist in charge of the patients. Margareth Afonso Torres conducted HLA testing of the patients. Marcelo Maia Pinheiro, Felipe Moura Maia Pinheiro and Margareth Afonso Torres wrote and critically revised the manuscript.

\section{Acknowledgments}

The authors would like to thank the Clinical Laboratory of the Israelita Albert Einstein Hospital.

\section{References}

1 Imagawa A, Hanafusa T, Itoh N, Waguri M, Yamamoto K, Miyagawa J, Moriwaki M, Yamagata K, Iwahashi H, Sada M, et al. 1999 Immunological abnormalities in islets at diagnosis paralleled further deterioration of glycaemic control in patients with recent-onset Type I (insulin-dependent) diabetes mellitus. Diabetologia 42 574-578. (doi:10.1007/s001250051197)

2 Lindley S, Dayan CM, Bishop A, Roep BO, Peakman M \& Tree TI 2005 Defective suppressor function in CD4+ CD25+ T-cells from patients with type 1 diabetes. Diabetes 54 92-99. (doi:10.2337/ diabetes.54.1.92)

3 Daneman D 2006 Type 1 diabetes. Lancet 367 847-858. (doi:10.1016/ S0140-6736(06)68341-4)

4 Abdul-Rasoul M, Habib H \& Al-Khouly M 2006 The honeymoon phase'in children with type 1 diabetes mellitus: frequency, duration, and influential factors. Pediatric Diabetes 7 101-107. (doi:10.1111/ j.1399-543x.2006.00155.x)

5 Mortensen HB, Hougaard P, Swift P, Hansen L, Holl RW, Hoey H, Bjoerndalen H, de Beaufort C, Chiarelli F, Danne T, et al. 2009 New definition for the partial remission period in children and adolescents with type 1 diabetes. Diabetes Care 32 1384-1390. (doi:10.2337/dc08-1987) 
6 Kim SJ, Nian C, Doudet DJ \& McIntosh CH 2009 Dipeptidyl peptidase IV inhibition with MK0431 improves islet graft survival in diabetic NOD mice partially via T-cell modulation. Diabetes 58 641-651. (doi:10.2337/db08-1101)

7 Tian L, Gao J, Hao J, Zhang Y, Yi H, O’Brien TD, Sorenson R, Luo J \& Guo Z 2010 Reversal of new-onset diabetes through modulating inflammation and stimulating $\beta$-cell replication in nonobese diabetic mice by a dipeptidyl peptidase IV inhibitor. Endocrinology 151 3049-3060. (doi:10.1210/en.2010-0068)

8 Couri CE, Oliveira MC, Stracieri AB, Moraes DA, Pieroni F, Barros GM, Madeira MI, Malmegrim KC, Foss-Freitas MC, Simões BP, et al. 2009 $\mathrm{C}$-peptide levels and insulin independence following autologous nonmyeloablative hematopoietic stem cell transplantation in newly diagnosed type 1 diabetes mellitus. JAMA 301 1573-1579. (doi:10.1001/jama.2009.470)

9 Badenhoop K, Kahles H \& Penna-Martinez M 2012 Vitamin D, immune tolerance, and prevention of type 1 diabetes. Current Diabetes Reports 12 635-642. (doi:10.1007/s11892-012-0322-3)

10 Bonfanti R, Bazzigaluppi E, Calori G, Riva MC, Viscardi M, Bognetti E, Meschi F, Bosi E, Chiumello G \& Bonifacio E 1998 Parameters associated with residual insulin secretion during the first year of disease in children and adolescents with Type 1 diabetes mellitus. Diabetic Medicine 15 844-850. (doi:10.1002/(SICI)10969136(199810)15:10\&lt;844::AID-DIA679\&gt;3.0.CO;2-A)

11 Kumar KH, Shaikh A \& Prusty P 2013 Addition of exenatide or sitagliptin to insulin in new onset type 1 diabetes: a randomized, open label study. Diabetes Research and Clinical Practice 100 e55-e58. (doi:10.1016/j.diabres.2013.01.020)

12 Ellis SL, Moser EG, Snell-Bergeon JK, Rodionova AS, Hazenfield RM \& Garg SK 2011 Effect of sitagliptin on glucose control in adult patients with Type 1 diabetes: a pilot, double-blind, randomized, crossover trial. Diabetic Medicine 28 1176-1181. (doi:10.1111/j.14645491.2011.03331.x)

13 Farngren J, Persson M, Schweizer A, Foley JE \& Ahrén B 2012 Vildagliptin reduces glucagon during hyperglycemia and sustains glucagon counterregulation during hypoglycemia in type 1 diabetes. Journal of Clinical Endocrinology and Metabolism 97 3799-3806. (doi:10.1210/jc.2012-2332)

14 Lima-Martínez MM, Guerra-Alcalá E, Contreras M, Nastasi J, Noble JA \& Polychronakos C 2014 One year remission of type 1 diabetes mellitus in a patient treated with sitagliptin. Endocrinology, Diabetes and Metabolism Case Reports 2014 140072. (doi:10.1530/edm-14-0072)

15 Bengsch B, Seigel B, Flecken T, Wolanski J, Blum HE \& Thimme R 2012 Human Th17 cells express high levels of enzymatically active dipeptidylpeptidase IV (CD26). Journal of Immunology 188 5438-5447. (doi:10.4049/jimmunol.1103801)

16 Pinheiro MM, Diniz SN, Valduga CJ, Stoppa CL \& Gorjão R 2016 Sitagliptin modulates the immune response of mononuclear cells of human peripheral blood (PBMC). Poster 214-LB. New Orleans, USA: American Diabetes Association's 76th Scientific Sessions. (Available at: https://ada.apprisor.org/index.cfm?k=zzvtycxsin)

17 Zhao Y, Yang L, Wang X \& Zhou Z 2014 The New insights from DPP-4 inhibitors: their potential immune modulatory function in autoimmune diabetes. Diabetes/Metabolism Research and Reviews 30 646-653. (doi:10.1002/dmrr.2530)
18 Aso Y, Fukushima M, Sagara M, Jojima T, Iijima T, Suzuki K, Momobayashi A, Kasai K \& Inukai T 2015 Sitagliptin, a DPP-4 inhibitor, alters the subsets of circulating CD4+ T cells in patients with type 2 diabetes. Diabetes Research and Clinical Practice 110 250-256. (doi:10.1016/j.diabres.2015.10.012)

19 Nishioka T, Shinohara M, Tanimoto N, Kumagai C \& Hashimoto K 2011 Sitagliptin, a dipeptidyl peptidase-IV inhibitor, improves psoriasis. Dermatology 224 20-21. (doi:10.1159/000333358)

20 Lynch M, Tobin AM, Ahern T, O'Shea D \& Kirby B 2014 Sitagliptin for severe psoriasis. Clinical and Experimental Dermatology 39 841-842. (doi:10.1111/ced.12408)

21 Kandasamy N, Lennox G, Annamalai A, Maguire G \& Adler A 2012 Sitagliptin in glutamic acid decarboxylase antibody-positive diabetes mellitus. Endocrine Practice 18 e65-e68. (doi:10.4158/EP11340.CR)

22 Zhao Y, Yang L, Xiang Y, Liu L, Huang G, Long Z, Li X, Leslie RD, Wang X \& Zhou Z 2014 Dipeptidyl peptidase 4 inhibitor sitagliptin maintains $\beta$-cell function in patients with recent-onset latent autoimmune diabetes in adults: one year prospective study. Journal of Clinical Endocrinology and Metabolism 99 E876-E880. (doi:10.1210/ jc.2013-3633)

23 Mathieu C \& Badenhoop K 2005 Vitamin D and type 1 diabetes mellitus: state of the art. Trends in Endocrinology and Metabolism 16 261-266. (doi:10.1016/j.tem.2005.06.004)

24 EURODIAB Substudy 2 Study Group 1999 Vitamin D supplement in early childhood and risk for Type I (insulin-dependent) diabetes mellitus. Diabetologia 42 51-54. (doi:10.1007/s001250051112)

25 Rapti E, Karras S, Grammatiki M, Mousiolis A, Tsekmekidou X, Potolidis E, Zebekakis P, Daniilidis M \& Kotsa K 2016 Combined treatment with sitagliptin and vitamin $\mathrm{D}$ in a patient with latent autoimmune diabetes in adults. Endocrinology, Diabetes and Metabolism Case Reports 2016 150136. (doi:10.1530/edm-15-0136)

26 Li X, Liao L, Yan X, Huang G, Lin J, Lei M, Wang X \& Zhou Z 2009 Protective effects of 1 - $\alpha$-hydroxyvitamin D3 on residual $\beta$-cell function in patients with adult-onset latent autoimmune diabetes (LADA). Diabetes/Metabolism Research and Reviews 25 411-416. (doi:10.1002/dmrr.977)

27 Takeda Y, Fujita Y, Honjo J, Yanagimachi T, Sakagami H, Takiyama Y, Makino Y, Abiko A, Kieffer TJ \& Haneda M 2012 Reduction of both beta cell death and alpha cell proliferation by dipeptidyl peptidase- 4 inhibition in a streptozotocin-induced model of diabetes in mice. Diabetologia 55 404-412. (doi:10.1007/s00125-011-2365-4)

28 Riachy R, Vandewalle B, Belaich S, Kerr-Conte J, Gmyr V, Zerimech F, d'Herbomez M, Lefebvre J \& Pattou F 2001 Beneficial effect of 1,25 dihydroxyvitamin D3 on cytokine-treated human pancreatic islets Journal of Endocrinology 169 161-168. (doi:10.1677/joe.0.1690161)

29 Gysemans CA, Cardozo AK, Callewaert H, Giulietti A, Hulshagen L, Bouillon R, Eizirik DL \& Mathieu C 2005 1,25-Dihydroxyvitamin D3 modulates expression of chemokines and cytokines in pancreatic islets: implications for prevention of diabetes in nonobese diabetic mice. Endocrinology 146 1956-1964. (doi:10.1210/en.2004-1322)

30 Tridgell DM, Spiekerman C, Wang RS \& Greenbaum CJ 2011 Interaction of onset and duration of diabetes on the percent of GAD and IA-2 antibody-positive subjects in the Type 1 Diabetes Genetics Consortium Database. Diabetes Care 34 988-993. (doi:10.2337/dc10-1903)

Received in final form 23 November 2016

Accepted 30 November 2016 